\title{
Power Quality Improvement in Smart Grid using SPWM Inverter and Shunt Active Power Filter
}

\author{
Neha GL ${ }^{1}$, Dr. Basavaraja Banakara ${ }^{2}$ \\ PG Student, Dept of Electrical Engineering, University BDT College of Engg, Davangere, India ${ }^{1}$ \\ Professor, Dept of Electrical Engineering, University BDT College of Engg, Davangere, India ${ }^{2}$
}

\begin{abstract}
In present scenario, the use of non-conventional energy resources and non-linear loads in to the electric grid is been increasing and it has a adverse effect on power quality issues and also energy management. As a result there will be increase in harmonic distortion, frequent switching of load and hence the flicker formation. Power quality plays a major role in smart grid design and operation. The major reason behind this is, active participation of consumers in the power sector and increased usage of non-conventional energy resources in to the smart grid. This power grid must necessarily overcome the power quality challenges, So as to avoid barriers against introduction of new technology. This paper overviews the power quality problems and presents the controlling scheme using SPWM inverters and Shunt active power filters (APF) in order to enhance power quality in the smart grid. The Simulation is carried out using MATLAB simulink.
\end{abstract}

Keywords: Sinusoidal pulse width modulation (SPWM), harmonic distortion, flicker, power quality, Active power filter (APF).

\section{INTRODUCTION}

Modern society is heavily dependent on the electric supply. For safe and efficient operation of end user equipment, a good quality and continuity of electric power supply is very much essential .Basically, concepts of smart grid arrived from many innovative technologies in the power industry. smart grid mainly includes renewable energy sources, distributed generation, information and communication technology. Due to the advancement in the renewable energy penetration technology, wind power penetration has been increased in few portions of the system. These advancements are also anticipated in PV systems. Old version of control and communication systems are need to be updated, so as to accommodate for increasingly penetrating renewable energy resources. Power quality attains a major role in smart grid, which cannot be neglected [1] .To get good compatibility between all the equipments connected to the grid, a adequate power quality is essential. Hence this issue place a major role in capable working of present as well as upcoming grids.

\section{POWER QUALITY PROBLEMS}

In this section, some of the power quality problems are discussed.

- Voltage sags (or Dips)

Voltage sag is reduction in RMS voltage for short duration. Sometimes at load end heavy current is drawn, due to this voltage sags are formed.

- Long interruptions

In power system network, failure of equipment due to storms, fire, disoperation of protective devices causes long interruptions. And this interruptions of electrical systems will get prolonged for a period longer than 1 or 2 seconds.

- voltage spikes

A rapid deviation of voltage for a duration within distinct micro seconds forms the voltage spikes. Even for low voltage, these variations will reach thousands of volts. These are mainly caused due to lightning ,line switching, sudden disposal of heavy loads.

- Voltage swell

With a period greater than one cycle, less than few seconds and the power frequency exceeding the normal tolerance level ,there will be fugitive increase in voltage, this can be termed as voltage swell. 
- Harmonic Distortion

Non-linear loads like SMPS, power electronic equipments, data operating devices cause periodic distortion of voltage or current waveform, this forms the harmonic distortion.

- Voltage fluctuations

A series of voltage variations caused by rapid start or stop of electric motors, oscillatory loads can be termed as voltage fluctuation. Voltage variation will be within a range of 0.9 to 1.1 p.u.

- Noise

Noise is set over of high frequency unwanted signals on the waveform of power system frequency.

- Voltage Unbalance

If voltage magnitudes and phase angle difference is not equal in a three phase system, then it causes maximum voltage variation, which can be termed as voltage unbalance.[2]

\section{TOPOLOGY FOR POWER QUALITY IMPROVEMENT}

This topology consists of wind power source, PV system, three phase source, Fuel cell, PWM inverter, Shunt active power filter and non-linear load. Due to non-linear loads, harmonic distortions will be induced in the system, and hence create adverse effect on power quality. For improving power quality, the control architecture used here is mainly based on voltage source inverter, operated in sinusoidal pulse width modulation technique. But to eradicate complete distortions, a shunt active power filter is used at the point of common coupling. To cancel the harmonics and compensate for the reactive power, an active power filter is used. The shunt active power filter is a device that is connected in parallel to and cancels the reactive and harmonic currents from a non-linear load. The resulting total current drawn from the ac main is sinusoidal.

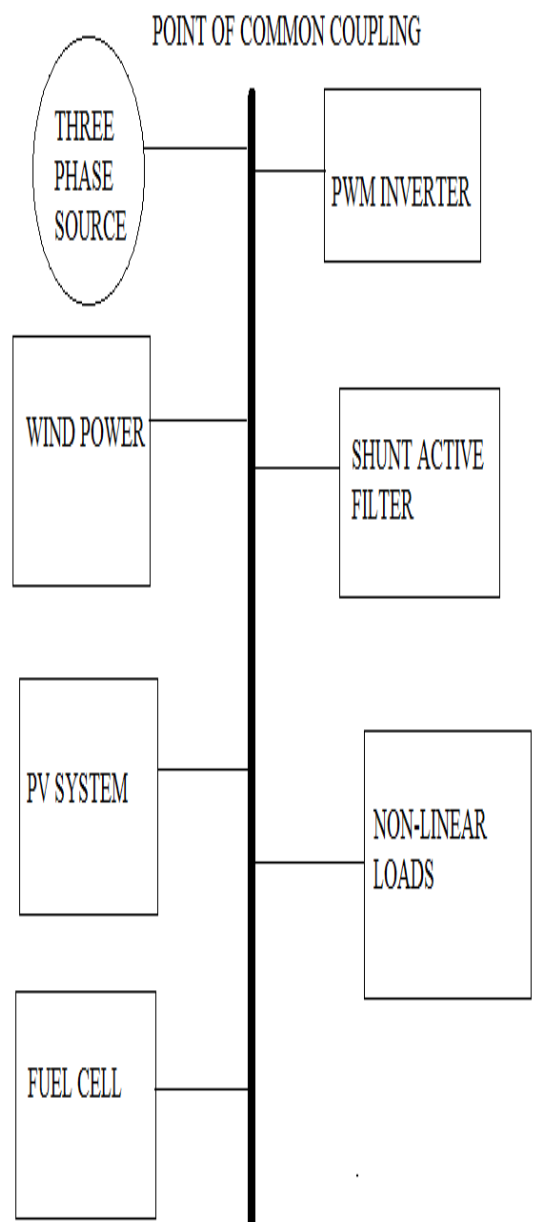

Fig 1 Topology for Power quality improvement 


\section{ISO 3297:2007 Certified}

Vol. 5, Issue 4, April 2017

Ideally, the APF needs to generate just enough reactive and harmonic current to compensate the nonlinear loads in the line. In an APF, a voltage source inverter is used to generate the compensating current and is injected in to the utility power source grid. This cancels the harmonic components drawn by the non-linear load and keeps the utility line current sinusoidal.

\section{SINUSOIDAL PULSE WIDTH MODULATION TECHNIQUE}

The voltage source inverter manipulated here mainly adopts the sinusoidal PWM technique which uses the DC input voltage of constant magnitude. Here the venture of the converter is to govern the frequency and magnitude of DC to AC converted output. In order to curb the inverter, modulation strategies are used which mainly determine the efficiency parameter of inverter such as switching losses and harmonic reduction. In accordance with the sine function, the inverter output voltage and frequency can be controlled by using SPWM technique [3]-[5]. In SPWM technique each period is characterized by constant amplitude pulses, but with different duty cycles. Here in order to reduce harmonic content and to control the output voltage, width of the pulses are modulated. In SPWM to generate the PWM signal, three sine waves and a triangular carrier wave of high frequency is used. The sinusoidal waves of 120 deg phase difference with each other can be considered as the reference signal. Based on the requirement of inverter output frequency, the frequency of sinusoidal waves is chosen. A wave with high frequency is considered as triangular wave. By analyzing the comparison between sinusoidal wave and triangular wave, generation of switching signal takes place. When sine voltage exceeds the triangular voltage, comparator generates a pulse and it is used in triggering of respective inverter switches. And hence the voltage regulation and harmonic reduction takes place.

\section{V.SIMULINK MODEL}

Fig 2 shows the MATLAB simulink model to improve power quality in smart grid. This model consists of wind, solar systems, fuel cells integrated in to the grid. Non-linear load is considered to create disturbances in the system. And SPWM inverter, shunt active power filter is synchronized to reduce distortions in the system.

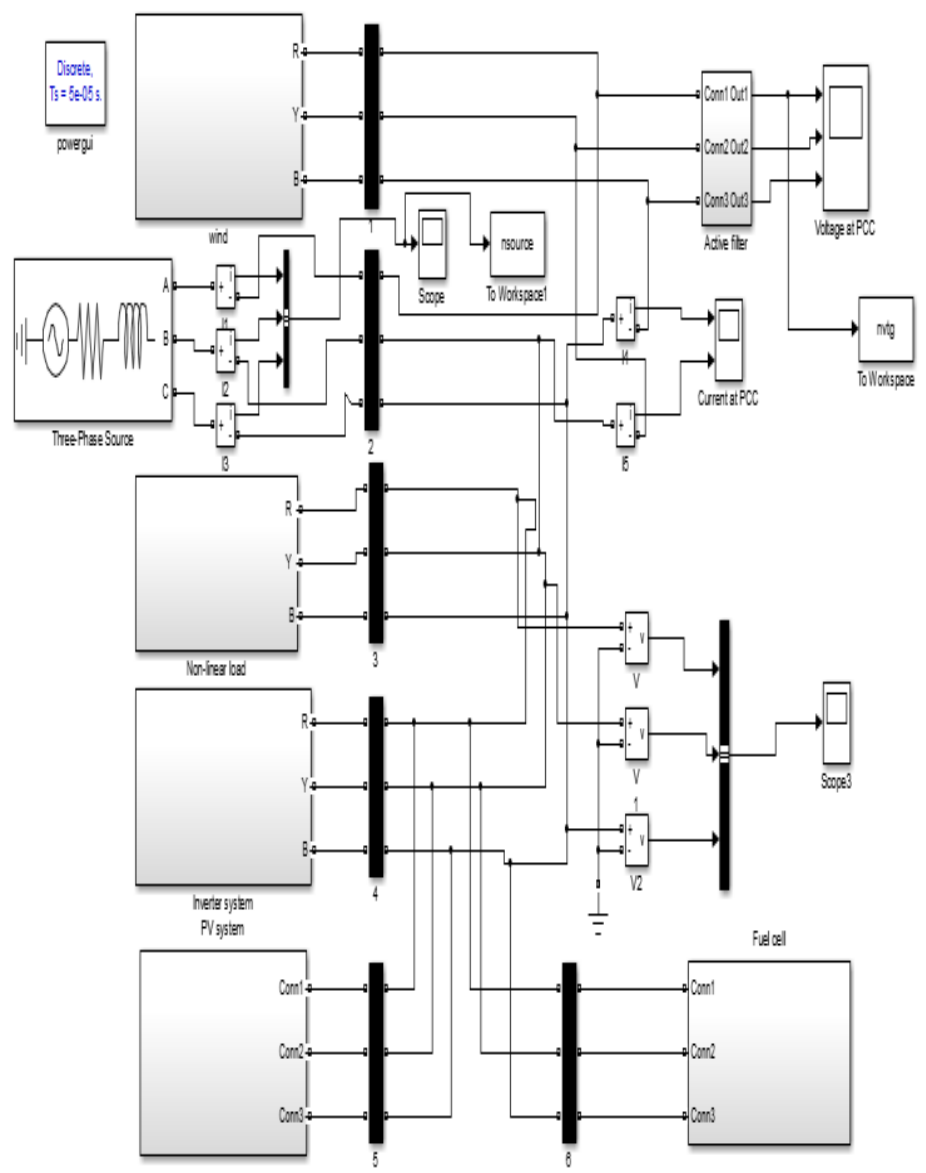

Fig 2 Simulink model for power quality improvement in smart grid 


\section{ISO 3297:2007 Certified}

Vol. 5, Issue 4, April 2017

\section{SYSTEM PERFORMANCE}

MATLAB SIMULINK is used for simulation purpose. Multiple sources are adopted here for smart grid integration such as wind, PV systems, Fuel cell. And also non-linear loads are considered to create distortion. Due to non-linear loads, harmonic distortions are generated in current waveform, which results in voltage waveform distortion as well. Under such condition voltage and current waveforms are not proportional to each other. To overcome the above mentioned problem, SPWM inverter along with shunt active filter is adopted here. In SPWM technique each period is characterized by constant amplitude pulses, but with different duty cycles. Here in order to reduce harmonic content and to control the output voltage, width of the pulses are modulated. But a pure sine current waveform cannot be attained by SPWM; hence in addition to this a shunt active power filter is connected at point of common coupling.

\section{RESULTS \& DISCUSSION}

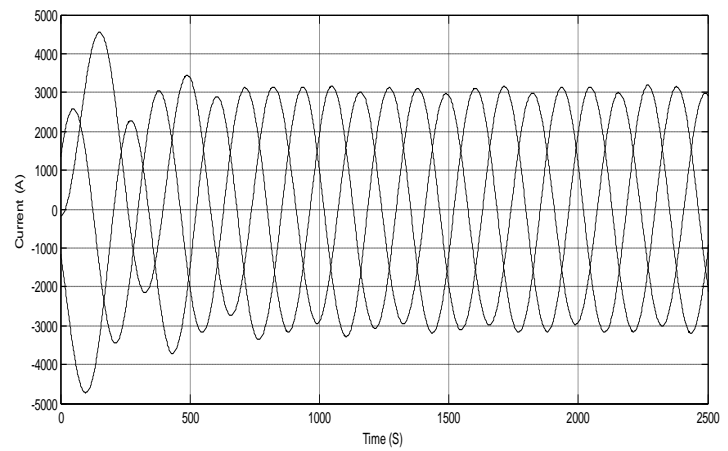

Fig 3 (a) Source current

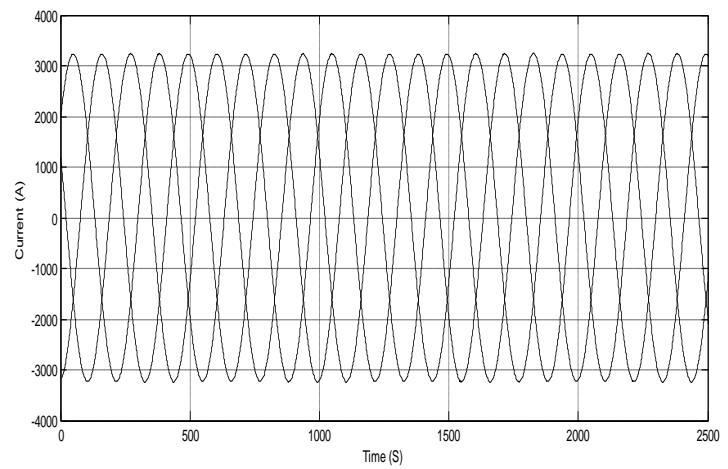

Fig 3 (b) Source current

Fig 3 (a) and 3 (b) shows the source current waveform before and after applying control strategy respectively . From the figure we can observe that initially there are some distortions, but when controlling technique is adopted waveform will become pure sinusoidal as shown in fig 3(b).

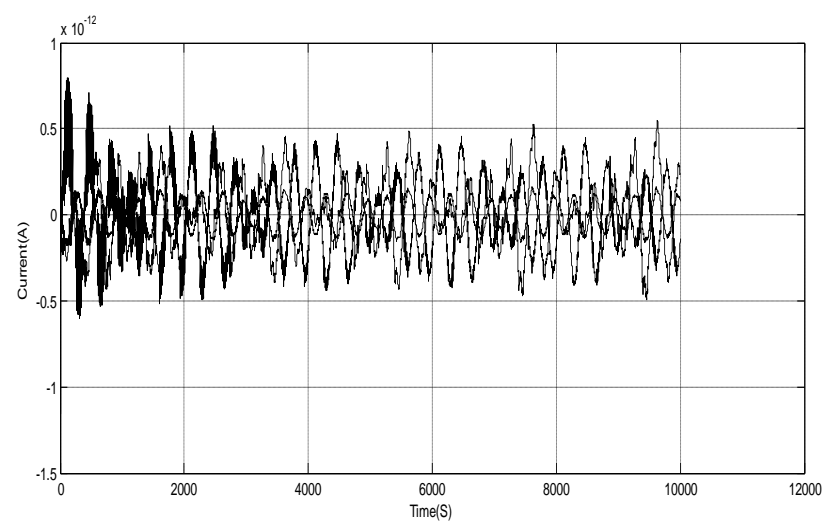

Fig 3 (c) Inverter current 


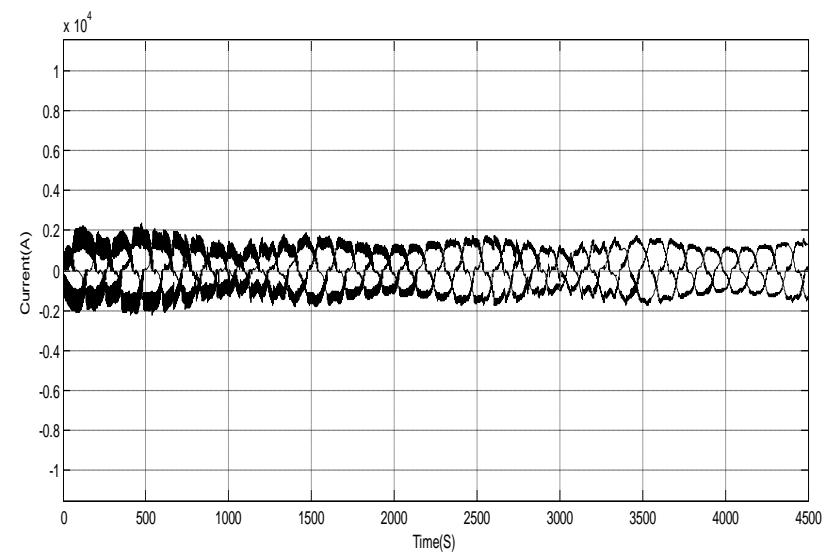

Fig 3 (d) Load current

Fig 3 (d) shows the load current waveform. As non-linear load is considered here, we can observe harmonics in the load current waveform.

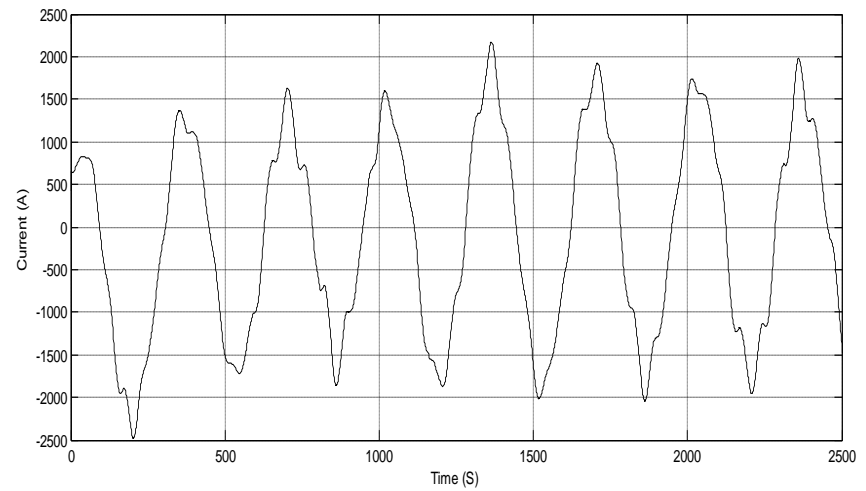

Fig 3 (e) Current at PCC without applying control strategy

Fig 3 (e) shows the current at point of common coupling without applying control using SPWM and shunt active power filter. So there are certain distortions in the current waveform

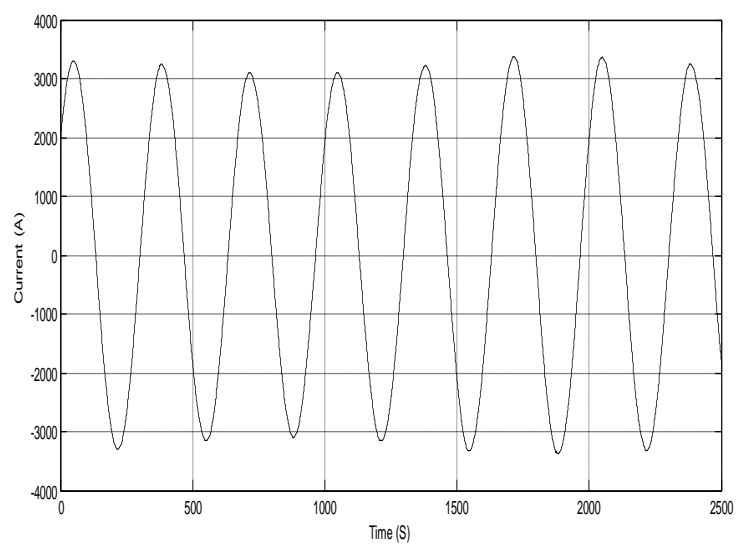

Fig 3 (f) Current at PCC with applied control strategy

Fig 3 (f) shows the waveform of current at the PCC by applying control using SPWM and shunt active power filter. In the fig 3 (e) we can observe the distortions in the sinusoidal wave. In order to overcome that problem, control strategies of SPWM and shunt active power filter is applied here. Hence a pure sinusoidal wave is attained as shown in fig 3(f). And it is a sign of good power quality. 


\section{International Journal of Innovative Research in} Electrical, Electronics, Instrumentation and Control Engineering

\section{ISO 3297:2007 Certified}

Vol. 5, Issue 4, April 2017

\section{CONCLUSION}

This paper mainly interprets the power quality improvement in the smart grid. The system is integration of multiple sources to the grid, connected with non-linear load is considered and identified some harmonic distortions and hence leads to power quality disturbances in the system. In order to enhance the power quality in the smart grid power system, voltage source converter based on sinusoidal pulse width modulation (SPWM) technique along with shunt active power filter is adopted and the output waveforms are analyzed by modulating pulse width in the SPWM inverter and hence distortions can be reduced, but in order to eradicate maximum distortions, shunt active power filter is synchronized in the circuit. In this paper we have carried out detailed analysis of different current waveforms at point of common coupling without control scheme and then by applied control scheme using SPWM and shunt active power filter by using MATLAB simulation and noticed the power quality enhancement in the smart grid power system.

\section{REFERENCES}

[1] Smart Grids, European technology platform for the electricity networks of the future. http://www.smartgrids.eu/

[2] Shalini Bajpai "Power Quality Improvement using Ac to Ac PWM converter for Distribution Line" International Journal of computational Engineering Research,vol. 3.Issue 7, July 2013.

[3] Rajesh Kumar Ahuja ,Amit kumar " Analysis Design and control of sinusoidal PWM Three Phase voltage source Inverter Feeding Balanced Loads at Different Carrier Frequencies using MATLAB" International Journal of Advanced Research in Electrical, Electronics and Instrumentation Engineering Vol.3, Issue 5,May 2014.

[4] J.M. Guerrero, J.C. Vasquez, J . Matas, M.Castilla and L. Garcia Vicuna, "Hierarchical control of Droop controlled AC and DC Microgrids- A general approach Towards standardization", IEEE Ind. Electron., vol 58,No.1,January 2011.

[5] J .He, Y. W. Li, and M.S. Munir, " A flexible harmonic control approach through voltage controlled DG-grid interfacing converters," IEEE Trans.Ind.Electron.,vol.59, no.1, pp.444-455, Jan.2012

\section{BIOGRAPHIES}

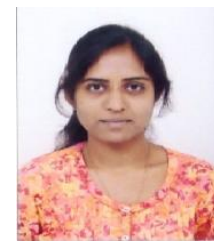

Neha G.L, Obtained BE degree from VTU in 2015. Currently pursuing master degree in University BDT college of Engineering, Davangere, Karnataka, India.

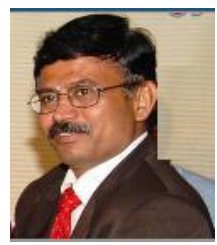

Dr. Basavaraja Banakara - ME, PhD (NITW), MBA (HR), Senior Member EEE, SMIACSIT, LMISTE, MIAENG, Fellow IEI Executive Committee Member for ISTE AP Section. He was born in 1970 .He completed his engineering (EEE) degree from Gulbarga university, Master degree from Karnataka university, India and he obtained his Doctoral program at NIT, Warangal, India. He is presently working as Professor, Placement \& training officer in UBDTCE, Davangere, Karnataka, India. He also dedicated his meritorious service in following institutes, Lecturer in VEC Bellary, Professor at SR Engineering College Ananthasagar, Waranagal ,Associate Professor at SSJ Engineering College Mahaboobnagar, Principal at Padmasri Dr.BV Raju Institute of Technology, Narasapur, AP, India, Professor \& Director for Academic Registration at KL University, Guntur, AP, India, Professor \& VicePrincipal at GITAM University Hyderabad, AP, India. He has keen interest towards areas like Power Quality, power electronics and drives, High voltage Engineering, EMTP applications, Micro-grids. In national and international journals as well as in conferences he presented 92 publications. 